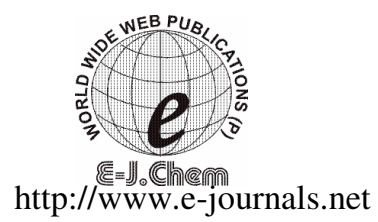

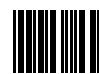

ISSN: 0973-4945; CODEN ECJHAO

E-Journal of Chemistry

2010, 7(S1), S344-S348

\title{
Validated UV-Spectrophotometric Methods for Determination of Gemifloxacin Mesylate in Pharmaceutical Tablet Dosage Forms
}

\author{
R ROTE AMBADAS* and P. PINGLE SUNITA \\ Department of Pharmaceutical Chemistry, M. G. V.'s Pharmacy College, Panchavati \\ Mumbai - Agra Road, Nashik- 422003, Maharashtra, India. \\ roteambadas@gmail.com
}

Received 19 February 2010; Accepted 1 May 2010

\begin{abstract}
Two simple, economic and accurate UV spectrophotometric methods have been developed for determination of gemifloxacin mesylate in pharmaceutical tablet formulation. The first UV-spectrophotometric method depends upon the measurement of absorption at the wavelength $263.8 \mathrm{~nm}$. In second area under curve method the wavelength range for detection was selected from $268.5-258.5 \mathrm{~nm}$. Beer's law was obeyed in the range of 2 to $12 \mu \mathrm{gmL}^{-1}$ for both the methods. The proposed methods was validated statistically and applied successfully to determination of gemifloxacin mesylate in pharmaceutical formulation.
\end{abstract}

Keyword: Gemifloxacin mesylate, UV-Spectrophotometry, AUC,

\section{Introduction}

Gemifloxacin (R, S)-7(3-aminomethyl-4-syn-methoxyimino-1-pyrrolidinyl)-1-cyclopropyl-6fluro-1, 4 dihydro-4-oxo-1, 2 naphthyridine-3-carboxylic acid is a new fluroquinolone antibacterial compound with enhanced affinity for bacterial topoisomerase IV and has been developed for the treatment of respiratory and urinary tract infection. The compound has a broad spectrum of activity against gram-positive and gram-negative bacteria. Literature survey revealed that few analytical method have been reported for the estimation of gemifloxacin mesylate including utility of $\sigma$ and $\pi$-acceptors for the spectrophotometer determination of gemifloxacin mesylate in pharmaceutical formulation ${ }^{1}$, rapid determination in human plasma by HPLC-MS-MS ${ }^{2,3}$, rapid and sensitive LC method for analysis of gemifloxacin in human plasma $^{4}$, spectrophotometric determination of gemifloxacin mesylate in pharmaceutical formulation trough ion-pair complexation ${ }^{5}$ and validated stability indicating assay of gemifloxacin and lomefloxacin in tablet formulation by capillary electrophoresis ${ }^{6}$. Gemifloxacin mesylate is not official in any pharmacopoeia. These developed proposed methods are simple, rapid and sensitive. 


\section{Experimental}

Pharmaceutical grade gemifloxacin mesylate was supplied by Matrix. Pharma Ltd., Sinner, Maharashtra, India and hydrochlorothiazide was supplied by Ajanta. Pharma, Paithan, Maharashtra, India. The methanol was purchased from Qualligens Fine Chemicals, Mumbai, India. Commercially available tablets Gem one (equivalent to $320 \mathrm{mg}$ of gemifloxacin mesylate) of Dr. Reddy was purchased from market for analysis.

\section{Instrumentation}

Shimadzu UV-2450 double beam spectrophotometer with $1 \mathrm{~cm}$ path length supported by Shimadzu UV-Probe software, version 2.21 was used for all spectrophotometric estimations. Shimadzu balance (AUW-120D) was used for all weighing.

\section{Preparation of standard solution of gemifloxacin mesylate}

Standard stock solution of gemifloxacin mesylate was prepared by dissolving $25 \mathrm{mg}$ of gemifloxacin mesylate in $25 \mathrm{~mL}$ of methanol to get concentration of $1.0 \mathrm{mg} \mathrm{mL}^{-1}$ in volumetric flask. Ten $\mathrm{mL}$ of stock solution was further diluted to $100 \mathrm{~mL}$ with methanol to get a working standard solution of concentration $100 \mu \mathrm{g} \mathrm{mL} \mathrm{L}^{-1}$. This solution used as standard working solution.

\section{Tablet sample preparation}

Ten tablets were weighed accurately and powdered. Powder equivalent to $10 \mathrm{mg}$ of gemifloxacin mesylate was weighed and transferred to $100 \mathrm{~mL}$ volumetric flask. Then it was dissolved in $25 \mathrm{~mL}$ of methanol by shaking the flask for 15 minutes and volume was made up to the mark with distilled water. The solution was filtered through Whatmann filter paper no. 41. A $1 \mathrm{~mL}$ aliquot of sample stock solution was transferred to $10 \mathrm{~mL}$ standard volumetric flask and volume was made up to mark with distilled water. Procedure was repeated five times for analysis of sample solution.

\section{Results and Discussion}

\section{Measurement of UV spectra}

From the working stock solutions appropriate dilutions of gemifloxacin mesylate were made with distilled water. Solutions were scanned in the wavelength range of $400-200 \mathrm{~nm}$ and recorded the UV-Spectrum of gemifloxacin mesylate using distilled water in the reference cell. The recorded UV- Spectrum of gemifloxacin mesylate, showed $\lambda_{\max }$ at $263.8 \mathrm{~nm}$ (Figure 1).

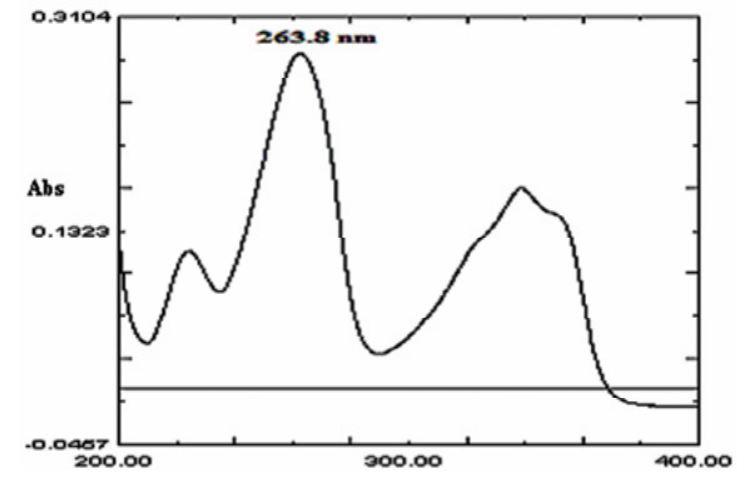

Figure 1. Zero order UV spectrum of gemifloxacin mesylate, $4 \mu \mathrm{mL}^{-1}$. 


\section{Method validation}

\section{Linearity}

The wavelengths selected should be such that at one the wavelength having same $\lambda_{\max }$ at different concentration of one of the drug, hence from the spectra of gemifloxacin mesylate $263.8 \mathrm{~nm}$ were selected as wavelength of detection for proposed method shown in Figure 1. The concentration range over which the drugs obeyed Beer's law was 2 to $12 \mu \mathrm{g} \mathrm{mL}^{-1}$ for gemifloxacin mesylate. The equation for calibration curve of gemifloxacin mesylate is $\mathrm{y}=0.0604 \mathrm{x}+0.0256$ and correlation coefficients is 0.9991 (Table 1$)$.

Table 1. Linearity of gemifloxacin mesylate.

\begin{tabular}{lcc}
\hline \multicolumn{1}{c}{ Parameter } & UV-Spectrophotometric method & AUC method \\
\hline Beers law range, $\mu \mathrm{g} \mathrm{mL}^{-1}$ & $2-12$ & $2-12$ \\
Intercept & 0.0256 & 0.0275 \\
Slope & 0.0604 & 0.00134 \\
Correlation coefficient & 0.9991 & 0.9983 \\
Limit of detection (LOD), $\mu \mathrm{g} \mathrm{mL}^{-1}$ & 0.12 & 0.12 \\
Limit of quantitation (LOQ), $\mu \mathrm{g} \mathrm{mL}^{-1}$ & 0.37 & 0.37 \\
\hline
\end{tabular}

\section{Precision and accuracy}

The proposed method was used for the determination of drug in tablets and results indicating satisfactory recoveries and high precision (Table 2).

Table 2. Result of analysis of commercially available tablet of gemifloxacin mesylate byUV-spectrometric and AUC method.

\begin{tabular}{ccc}
\hline Parameter & UV-spectrophotometric method & AUC method \\
\hline Labelled claim mg tablet $^{-1}$ & 320 & 320 \\
$\%$ mean $(\mathrm{n}=5)$ & 101.20 & 101.80 \\
Standard deviation & 1.20 & 1.12 \\
Standard Error & 0.539 & 0.504 \\
\hline
\end{tabular}

Precision of the method was evaluated with five replicates of standard solution of $10 \mu \mathrm{g} \mathrm{mL}^{-1}$ of gemifloxacin mesylate. The relative standard deviation value for gemifloxacin mesylate was found to be 0.63 and 1.83 for intra-day and inter-day precision. Inter-day precision and accuracy of the method was tested for 3 days at the same concentration levels. Percentage recoveries for gemifloxacin mesylate are shown in Table 3.

Table 3. Accuracy and precision of gemifloxacin mesylate by UV-spectrophotometric and AUC- method.

\begin{tabular}{ccccc}
\hline \multirow{2}{*}{ Accuracy/precision } & \multicolumn{2}{c}{ UV-spectrophotometric method } & \multicolumn{2}{c}{ AUC- method } \\
\cline { 2 - 5 } & \% Recovery & \% RSD & \% Recovery & \% RSD \\
\hline $0 \%$ & 101.24 & 0.77 & 100.60 & 1.24 \\
$100 \%$ & 100.23 & 1.70 & 101.91 & 0.19 \\
$150 \%$ & 99.86 & 1.17 & 98.43 & 1.17 \\
Intra-day precision & 99.57 & 0.552 & 100.19 & 0.65 \\
Inter-day precision & 100.23 & 0.828 & 99.87 & 1.80 \\
\hline
\end{tabular}




\section{AUC method}

\section{Measurement of UV spectra}

UV spectra for the solutions of gemifloxacin mesylate were recorded in a $10 \mathrm{~mm}$ cell over the range of $200-400 \mathrm{~nm}$ using distilled water in the reference cell. From the working stock solutions appropriate dilutions of gemifloxacin mesylate were made with distilled water. For the estimation of gemifloxacin mesylate by AUC method the wavelength ranges were selected from $268.8-258.8 \mathrm{~nm}(263.8 \pm 5 \mathrm{~nm})$ for gemifloxacin mesylate (Figure 2).

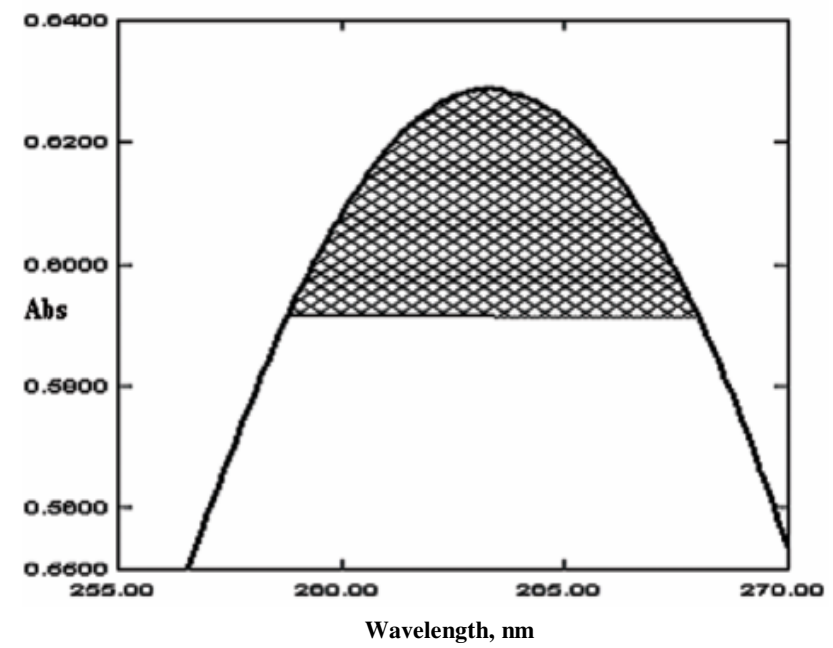

Figure 2.UV-spectrum for area under curve (AUC) of gemifloxacin mesylate, $4 \mu \mathrm{L} / \mathrm{mL}$ from $258.8-268.8 \mathrm{~nm}$.

\section{Method validation}

\section{Linearity}

The AUC of each drug was measured in the range of 258.8-268.8 $\mathrm{nm}$. The concentration range over which the drugs obeyed Beer's law was chosen 2 to $12 \mu \mathrm{g} \mathrm{mL}^{-1}$ for gemifloxacin mesylate. The equation for calibration curve of gemifloxacin mesylate was $\mathrm{y}=0.0275 \mathrm{x}+0.00134$ and correlation coefficients is 0.9983 . The LOD and LOQ values $0.123 \mu \mathrm{g} \mathrm{mL}-1$ and $0.374 \mu \mathrm{g} / \mathrm{mL}$ for montelukast sodium and levocetrizine dihydrochloride showed good precision of gemifloxacin mesylate for the proposed method (Table 1).

\section{Precision and accuracy}

The proposed method was used for the determination of drug in tablets and results indicating satisfactory recoveries and high precision (Table 2). Precision of the method was evaluated with five replicates of standard solutions of $10 \mu \mathrm{g} \mathrm{mL}$ of gemifloxacin mesylate. The percent relative standard deviation (\%RSD) values for gemifloxacin mesylate was found to be 0.552 and 0.828 for intra-day and inter-day precision. Interday precision and accuracy of the method was tested for 3 days at the same concentration levels. Percentage recoveries for gemifloxacin mesylate are shown in Table 3. 


\section{Conclusion}

UV spectrophotometric and AUC methods were developed and validated for the determination of gemifloxacin mesylate in pharmaceutical dosage forms. The selected methods were found to be sensitive, reproducible and accurate for the analysis of gemifloxacin mesylate in tablets. In general, both methods were found to be suitable for routine quality control of the drugs in a tablet dosage form.

\section{Acknowledgment}

Ajanta Pharma Ltd., Paithan, Maharashtra, India for providing hydrochlorothiazide and gemifloxacin mesylate by matrix Pharma, Sinner, Maharashtra, India as a gift sample for the research work. The authors are also thankful to Management and Principal of M.G.V's. Pharmacy College, Panchavati, Nashik, for providing necessary facilities.

\section{References}

1. Krishna M V and Dannana G S, E- J Chem., 2007, 5(3), 493.

2. Doyle E, Fowles S E, McDonnell D F and McCarthy R, J Chromatogr B, 2000, 746, 191-198.

3. Lee $\mathrm{W}$ and Yong C H, J Cromatogr A, 2000, 879, 113.

4. Pal K, Chakrabarty U S, Das A, Bhaumik U, Chatterjee B and Ghosh A, Chromatographia, 2009, 69(9/10), 853.

5. Krishna M V and Dannana G S, E-J Chem., 2007, 5(3), 515.

6. Elbashir A A and Saad B, J Liquid Chromatogr Relat Technol., 2008, 31, 1465. 


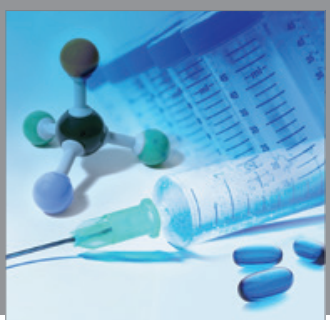

International Journal of

Medicinal Chemistry

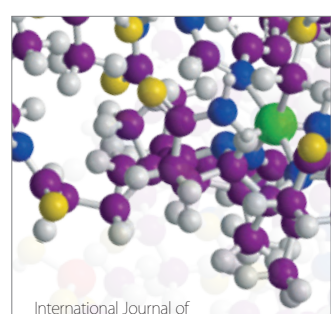

Carbohydrate Chemistry

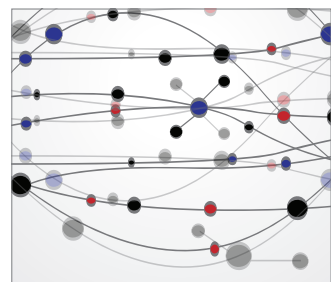

The Scientific World Journal
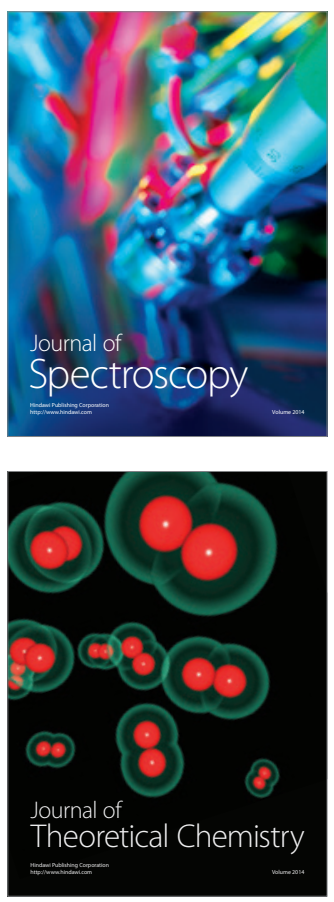
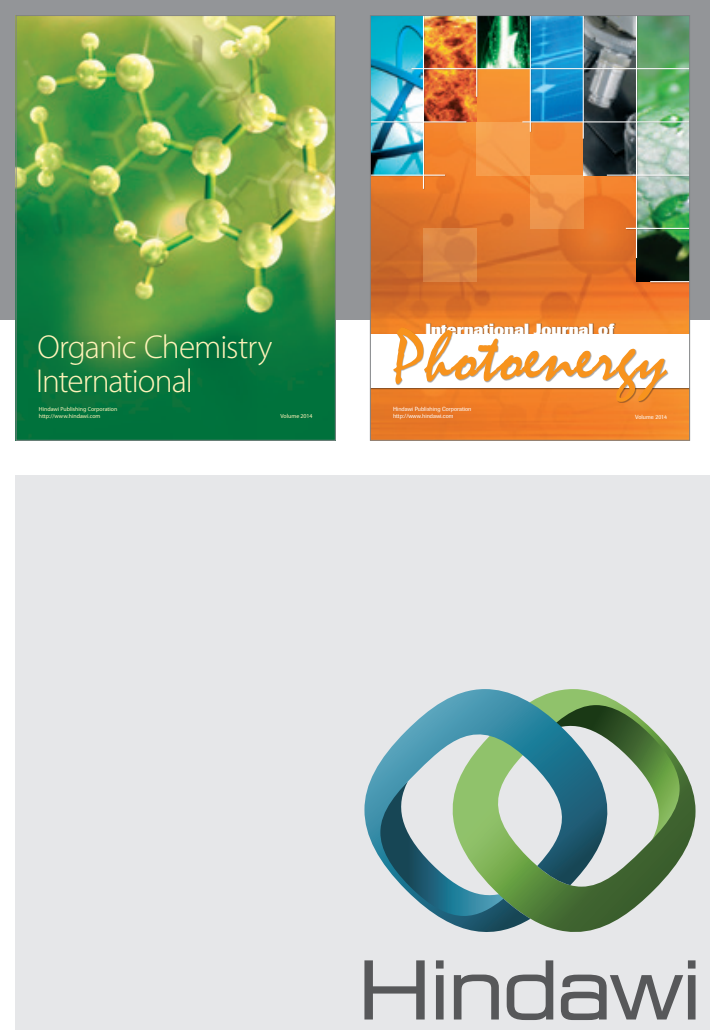

Submit your manuscripts at

http://www.hindawi.com
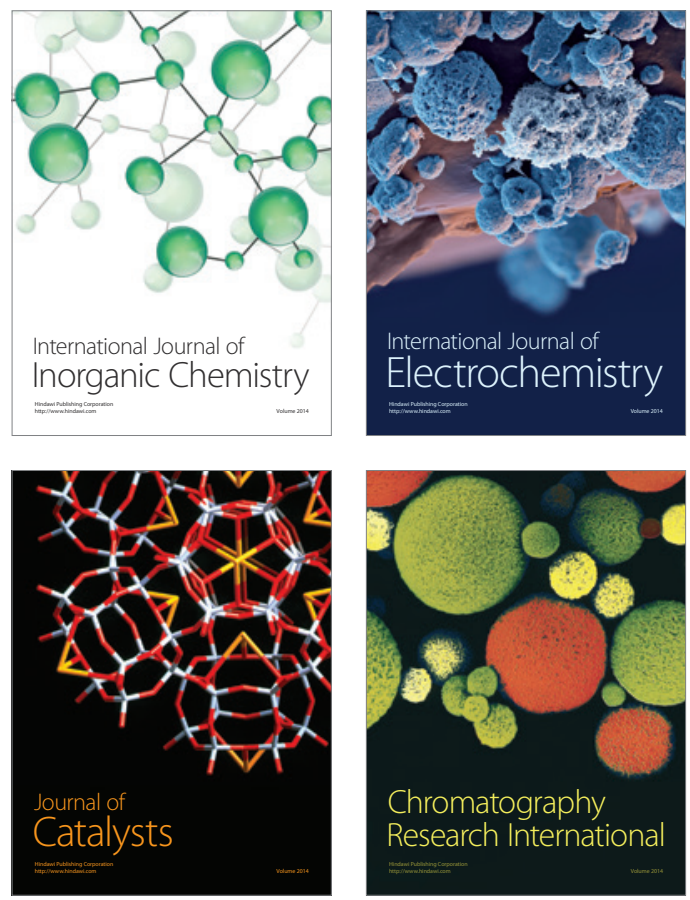
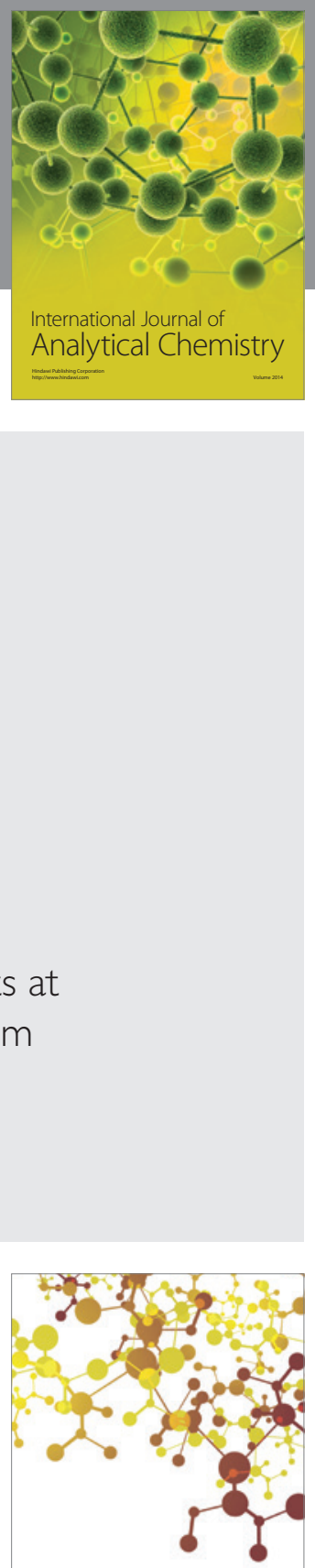

Journal of

Applied Chemistry
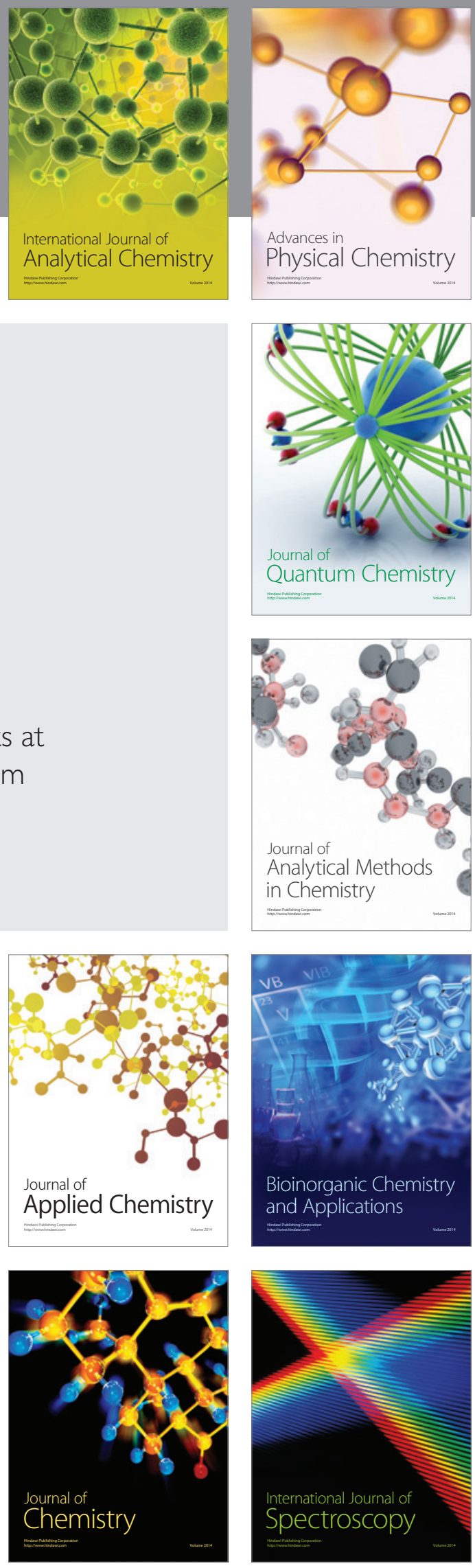